\title{
The view from above: The relevance of shared aerial drone videos for destination marketing
}

\begin{abstract}
The use of drones to produce videos has generated a large amount of visually appealing footage of various destinations. They attract much attention, but there are issues that affect their production, and their relevance to destination marketing. This research examines YouTube meta-data and spatial overlay analysis of shared aerial drone videos from the United Kingdom (UK). The results suggest that shared aerial drone videos have some unique user-generated content (UGC) characteristics and their spatial distribution tend to favor more populated areas. Theoretical and practical implications for destination marketing are further discussed.
\end{abstract}

Keywords: aerial drone videos; user-generated content (UGC); destination marketing; United Kingdom

\section{Introduction}

Despite the recent boom in the availability and use of drones (Goldman Sachs, 2016; Luppicini \& So, 2016), and recent research into their application in other sectors (Almeida et al., 2017; Beadel et al., 2018; Braitenberg et al., 2016; Stark, Vaughan, Evans, Kler, \& Goossens, 2018), their role in the tourism industry has received very little attention in the research literature (Hay, 2016; King, 2014; Mirk \& Hlavacs, 2014, 2015). This research is the first to analyze shared aerial drone videos from the perspective of tourism destination marketing.

Drone is a broad term used to describe any kind of unmanned aerial vehicle (UAV) that is remotely controlled or pre-programmed to fly autonomously, which can look like either a 
small airplane with fixed-wings or a small helicopter with multirotor systems (Vergouw, Nagel, Bondt, \& Custers, 2016). They can be controlled by mobile apps installed on smartphones or tablets, by wrist-worn devices, or by consoles as ground stations. Drones can be equipped with cameras, sensors and other electronics, providing live streaming or recording capabilities (King, 2014) Drones have uses with clear public benefits in the military, public safety, agricultural and industrial sectors (e.g., mapping and disaster management, surveillance, newsgathering, crime scene investigation) (Canis, 2015; Sandvik \& Lohne, 2014), as well as being used an increasing range of ways related to entertainment and commerce. These have included, for example, the use of drones to livestream and to monitor crowds at events (Sakiyama, 2017), to generate advertising footage for real estate developments (Babel, 2015) and to create dramatic footage for television and film (La Bella, 2016). Some uses of drones in sectors connected to, but not directly related to tourism, also provide benefits to the tourism industry, such as the use of drones in meteorology (PytlikZillig et al, 2016) or conservation (Bryan, 2017). An emerging area of drone use is delivery, with a number of retailers having investigated the possibilities of using drones for direct delivery of products to customers (Bamburry, 2015), although trials of these services have not progressed to viable mass-market offerings as yet.

The consumer drone market can be broken down into four distinct categories: aerial photography drones; toy drones; FPV (first person view) and racing drones; and hobbyist/hacker/developer drones (DroneDlyers, 2015). From these groups, the area of aerial filming was amongst the first commercial applications of drones (SESAR, 2016). The consumer and commercial drone market has seen significant growth in recent years (Global Market Insights, 2018; Luppicini \& So, 2016). Most drones in 2014 were bought by the U.S. (35\%), Europe (30\%) and China (15\%) (Majumdar, 2016). By 2020 it is expected that drone shipments will reach 7.8 million, versus 450,000 shipments in 2014 (Goldman Sachs, 2016). 
However, differences in rates of adoption are largely dependent on differing national regulations, relating to drone applicability, technical requirements, operational limitations, administrative procedures, human resource requirements and the implementation of ethical and legal constraints (Stöcker, Bennett, Nex, Gerke, \& Zevenbergen, 2017).

The tourism industry is a growth area for the use of drones (King, 2014; Mirk \& Hlavacs, 2015), but this has not been mirrored in the growth of research in this field. Recently, Hay (2016) presented a study which investigated general current and potential uses of drones in hospitality and tourism, with a summary of the possible future uses. To this end, Dinhopl and Gretzel (2016b) explore the differences related to the technology and social practices of (re)presentation between the well-established practice of tourist photography and the new practice of using wearable cameras and drones to film from different perspectives, while Aaron (2016) analyzed the motivations and experiences of participants who employ drones for tourism.

In contrast to this lack of research, tourism practitioners are increasingly involved in innovative tourism industry-specific drone use. Based on the emerging research literature and various practical examples, two main scenarios of drone application in tourism can be distinguished. First is the physical use of drones to provide some transactions, services or just fun for tourists. Second is the application of drones as a means for carrying and controlling equipment for sensing or recording terrestrial objects or activities at a destination to use these products for management or marketing purposes. The first scenario includes, for example, drones intervening in case of emergency or even as "flying tour guides" that tourists can follow (King, 2014). Some applications, such as delivery of goods or fast-food, flying billboards or dropping flyers at festivals, although they seemed promising in earlier phases of drone adoption, did not reach their full potential mostly due to security limitations, technical issues or being labeled as disruptive technology (Bamburry, 2015; Mancosu, 2016). For 
example, Rahman (2014) investigated the use of drones for assisting rescue services in a winter tourism context, and concluded that emerging technologies related to drones such as WiMAX and WiFi require further innovations before drones can be fully implemented within remote alpine settings.

The second scenario offers greater opportunities for the tourism industry. Mirk and Hlavacs $(2014,2015)$ explored the use of real-time video images of different places of the world made by drone-flying webcams. This form of virtual tourism with the help of drone videos, can present new access to tourism destinations and attractions for those unable to travel (Hay, 2016). Commercial drone producers market the necessary equipment for these virtual experiences from the same premise. For example, many new drones are now marketed as devices for filming traveler's adventurers and are also offered with the addition of virtual reality (VR) goggles for the direct streaming of drone flights (Garrett, 2017). The rising popularity of adventure and extreme tours (Ingga, 2016) supports these trends, as travelers, athletes or artists more frequently showcase their experiences using affordable quality recording equipment (e.g., GoPro cameras) for the creation of professional-quality independent videos, distributed via websites and social media in common with other kinds of user generated content in tourism (Munar \& Jacobsen, 2014; Tussyadiah \& Fesenmaier, 2009; Vannini \& Stewart, 2017).

According to Hay (2016), drone videos are of interest to destination marketing organizations (DMOs), complementing static images and short videos in presenting and promoting a destination. For example, New Zealand's DMO acquired drones to create its own videos (Dinhopl \& Gretzel, 2015) and subsequently created a successful social media campaign for sharing "ultimate holiday selfies" (Tourism New Zealand, 2015). The characteristics of destination videos shared on social media is relatively unexplored academic topic, either as separate media type (Crowel, Gribben, \& Loo, 2014; Huertas, 2018; 
Tussyadiah \& Fesenmaier, 2009) or as a part of other social media content types (Ulrike Gretzel, Fesenmaier, Lee, \& Tussyadiah, 2011; Kwok \& Yu, 2013; Månsson, 2011; Mariani, Di Felice, \& Mura, 2016). Lu et al. (2018) reviewed the research literature on social media and tourism and hospitality management published between 2004-2014 and found that only $1.9 \%$ of papers had engaged with the area of video within UGC, reflecting the relatively recent emergence of shared video content as an area of concern to tourism marketers.

When aerial drone videos are shared via social media sites they can be treated as other forms of user-generated content (UGC), such as text, pictures or audio. However, unlike other user-shared videos, the creation of drone videos encounters novel different technical and regulative limitations, as well as different users' motivations (Kreps, 2016), that mean that they can be considered as a specific type of UGC. Those specifics can be of relevance if aerial drone videos are considered as a means of destination marketing.

The overall aim of this research was to develop a greater understanding of this new form of UGC that will benefit researchers and practitioners, especially in terms of destination marketing. The three specific research objectives were to: 1 . Determine the general characteristics of shared aerial drone videos based on UGC metadata analysis; 2. Map the spatial distribution of shared aerial drone videos with a country to reveal spatial patterns; and to, 3. Discuss the relevance of these videos for destination marketing.

\section{Literature review}

\section{User-generated content in destination marketing}

UGC is media content created or produced by consumers rather than by paid professionals, and primarily shared online (Daugherty, Eastin, \& Bright, 2008). Johnson et al. (2012, p. 293) categorize the kinds of content posted in these websites as 'data in the form of text, 
photos, tags, audio or video created by an individual and hosted online where it is accessible to others'. User-generated content (UGC) has become an important source of information for tourists (Ayeh, Au, \& Law, 2013; Carvão, 2010; Chung \& Buhalis, 2008; Ulrike Gretzel \& Yoo, 2008) and can be situated on a variety of websites including social networks (e.g., Facebook), online travel communities (e.g., Lonely Planet), review sites (e.g., TripAdvisor), personal blogs, blog aggregators (e.g., Reddit), microblogging sites (e.g., Twitter, Weibo), wikis (e.g., WikiTravel) and video-hosting platforms (e.g., YouTube, Vimeo).

UGC can be shared both in 'real time' during a tourism experience or after the experience has ended (Munar \& Jacobsen, 2014), increasingly facilitated by the always-on nature of Internet-enabled smart devices carried by tourists. Content of this kind that relates to the experiences of tourists at destinations, attractions, or other sites has also been described as comprising part of 'electronic word of mouth' (eWOM), an aspect of marketing that has become increasingly important for tourism and hospitality businesses (Carvão, 2010; Litvin, Goldsmith, \& Pan, 2008; Rupert Hills \& Cairncross, 2011 as well as for tourism destinations (Urlike Gretzel, 2006; Marchiori \& Cantoni, 2015; Munar, 2011; Shen, Liu, Yi \& Li, 2016; Narangajavana, Callarisa Fiol, Moliner Tena, Rodríguez Artola, \& Sánchez García, 2017).

UGC has proven to be an effective way for companies and organizations to capitalize on the new relations created with consumers in the digital economy (Dickey \& Lewis, 2011). Before the emergence of Web 2.0, characterized by widespread social media usage, traditional "gatekeepers" such as newspaper editors, publishers and news shows had to digest information and report valuable content to the public in manageable ways. Nowadays, there are few or no "gatekeepers" to filter online content, and audiences can participate in new forms of dialogue online, and interact directly with businesses, institutions, and opinionformers (Chin-Fook \& Simmonds, 2011). 
Despite controversies over the reliability and credibility of UGC in tourism, especially concerning review sites such as TripAdvisor (Gao, Li, Liu, \& Fang, 2018), some research has found that UGC in eWOM for tourism can be perceived as more reliable than other forms of information (Fotis, Buhalis, \& Rossides, 2012) including that provided by businesses or destinations themselves, despite the fact that this does not appear to be true in other contexts such as retail (Ye, Law, Gu, \& Chen, 2011). UGC is frequently viewed by tourists as more akin to standard 'word of mouth' (WOM) recommendations from friends and family members (Wang, Yu, \& Fesenmaier, 2002; Yoo, Lee, Gretzel, \& Fesenmaier, 2009), despite more sophisticated consumers' ability to evaluate content in terms of its trustworthiness (Jin \& Phua, 2016). Chen et al. (2015, p. 964) found that eWOM 'plays a primary role in the consumer decision making process' and that consumers react more decisively to positive reviews than to negative ones. Mendes-Filho and colleagues, (2018) linked this trend to the increasing empowerment of independent travel consumers, a broader trend affecting the industry (Marine-Roig \& Anton Clavé, 2016). Despite this, Uşaklı (2017) found in a study of 50 European destination management organisations (DMOs), that social media and UGC are not being harnessed effectively in destination marketing, which has also been found to be the case with a sample of international DMOs (Roque \& Raposo, 2016). A study of 150 DMOs in France, Belgium and Switzerland found, for example, that only twenty percent of marketing budgets were spent on online content, with only $0.4 \%$ allocated to social media activities (Wozniak, Stangl, Schegg, \& Liebrich, 2017). These findings have significant implications for increasing DMO engagement with tourists - especially the generation of 'digital natives' (Gon, Pechlaner, \& Marangon, 2016) who expect to interact with businesses and each other using these means. Kang and Schuett (2013) sound a cautionary note, however, when advocating the engagement in UGC by DMOs, noting the inherent difficulties 
in controlling the quality and quantity of UGC on their in-house or independent social media platforms.

\section{Characteristics of drone videos as $U G C$}

In addition to traditional tourist photography, an increasing number of visitors have experience of recording videos during their vacations and later sharing these on social media sites (Tussyadiah and Fesenmaier, 2009). Video content has rapidly grown as a proportion of UGC online, as video-making devices have become more mainstream and video content has been integrated into other social media platforms such as Facebook and Twitter (Dinhopl and Gretzel, 2016a). Because of its specificity in technological and social practices, tourism videography can even be considered as a separate media form, different from travel photography (Dinhopl and Gretzel, 2015; Dinhopl and Gretzel, 2016b). From another perspective, using various social media sites, consumers now can easily search travel videos posted by other tourists and individuals, or by official DMOs, before making travel decisions (Lim et al., 2012). According to a USA-based study, two out of three consumers watch online travel videos when they are seeking information about their trips (Crowel et al., 2014).

Apart from the obvious perspective change, the use of drones has brought several changes to travel video creation. To summarize these changes, Table 1 presents descriptions of the most common views on the issue.

[Insert Table 1 about here]

The creation of drone videos, however, is characterized by specific technical (flight time, flight conditions, visual contact) and regulatory limitations (different restrictions on flights over densely populated areas, larger assembly of people, no-flight zones, privacy issues, 
ethics of the use, etc.), which can limit the spatial coverage of a destination (Kreps, 2016; Luppicini \& So, 2016). This can be contrasted with the growing popularity with DMOs of the less visually interesting, but nearly universal coverage offered by Digital Earth systems (Craglia et al., 2012) such as online satellite and aerial imagery, or Bing Bird's Eye (Bartha \& Kocsis, 2011), meaning that tourists can visually review almost any part of a destination. However, the method of the geo-localization of images and videos still remains a challenging task as many of Digital Earth systems are limited to highly-visited urban regions while large, but less populated geo-spatial regions are left behind (Zamir, Hakeem, Van Gool, Shah, \& Szeliski, 2016). In that sense, the spatial coverage capabilities of shared image and video repositories are important characteristic for destination marketing.

Many aerial drone video are professionally produced and so are, in some respects, not genuine UGC. However, if they are made publicly available (shared), regardless of the main motivation of a user to showcase a company's or entrepreneur's business activities, they make a contribution to the existing body of UGC for a destination. Unlike other types of UGC, such as pictures or general videos, aerial drone videos by default require additional techniques and efforts from their creators and therefore it is sometimes hard to delineate professional content from UGC. However, from the perspective of destination marketing, this delineation is not essential as the drone video's value will depend on the individual video's characteristics and the specific features of the destination.

\section{Methods}

The analysis in this paper is based on meta-data of United Kingdom (UK) aerial drone videos shared on YouTube and with added spatial references. This study focused on the UK for several reasons. The UK is, and will remain, one of the largest markets for drones in Europe, with a strong technology base, high levels of expertise, diverse industrial applications and an 
enthusiastic home market (EC, 2008; Goldman Sachs, 2016). The UK government is one of the first to set out a vision of a safe and proper use of drones in public and commercial services to contribute to the economy, create new jobs and encourage the development and learning of important new skills and rules of drone usage (Department for Transport, 2017). The sophistication and scale of the market for commercial and leisure drone use in the UK means that the research could draw on a large potential set of drone videos for analysis, and that recommendation could then be made for the use of destination drone videos in destinations in emerging drone markets.

\section{Sampling}

A purposive sample of drone videos of the United Kingdom was collected from YouTube. YouTube is world's largest online video sharing platform (Cheng, Liu, \& Dale, 2013; Bärtl, 2018), meaning that it was the most appropriate source for these videos, but it does not georeference videos by their locations which was necessary for this sampling strategy. To address this, the website TravelbyDron.com was used. This website allows consumers to share aerial drone videos uploaded on YouTube to a web-based map. TravelbyDron.com is currently world's largest collection of geo-located drone videos (TravelByDrone, 2017). Georeferenced drone videos clearly indicate the area in which the drone was used to film a destination and allowed for the identification of drone videos that were solely taken of the United Kingdom. Additionally, TravelbyDrone.com provides a quality check of drone videos. For example, videos that will not be included if they feature: poor editing, "roller-coaster"like or low-quality footage, are too long, overly promotional in nature, with animated intros or endings beyond 5-10s, military related footage, political, religious or other personal messages (TravelByDrone, 2017). In total, 614 drone videos that satisfy the above mentioned criteria were gathered. 


\section{YouTube meta-data analysis}

Given the absence of academic literature about the use of drone videos in tourism, this study was grounded on the existing common measurement variables for assessing social media videos and the measurement of user' engagement. The first stage of the analysis was carried out to determine the characteristics of aerial drone videos based on measurement metrics of general YouTube videos (Cheng, Liu, \& Dale, 2013; Thelwall, Sud, \& Vis, 2012). When uploading a video to YouTube, the user optimizes the metadata by choosing one of 15 selfexploratory categories where most people would expect to find the video, adds key words, key word phrases and tags (names, places, events, etc) that accurately describe video and writes an accurate and thorough description (IMP, 2012). Thus, for every drone destination video, the following data were collected: category; title; description; length; and age. Webometric Analyst (http://lexiurl.wlv.ac.uk/) software was used to retrieve drone video metadata from the YouTube API. The datasets were analyzed using SPSS statistical software.

\section{Spatial analysis}

The second part of research, dedicated to spatial analysis, followed the approach of variable selection, which had been applied in the case of user contributions of drone pictures on a photo sharing portal conducted by Hochmair and Zielstra (2015). ESRI's ArcGIS for Desktop software was used for data transformation and analysis. An overlay analysis and descriptive statistics were used for spatial analysis (Johnson \& Arrowsmith, 2015; Stankov et al., 2014). Four primary sources of data were used for this part of research: drone video locations; population density, land use and nationally designated areas in the UK. 
- Drone video locations were retrieved from TravebyDron.com using manual extraction of geographical coordinates from web-map HTML. Geographical coordinates were transformed in point shapefile, a basic vector-based impute data format for ArcGIS software.

- The population layer was in the form of gridded population, with a spatial resolution of 1x1 km for the UK, based on Census 2011 and Land Cover Map 2007 input data (Reis et al., 2016).

- Land used data was based on vector datasets for the UK, Jersey and Guernsey containing the Corine Land Cover (CLC) for 2012. Data was published by UK Centre for Ecology and Hydrology (Cole et al., 2015)

- For the protected areas, the nationally designated areas inventory (CDDA) polygon shapefile (version 14 for 2016) was obtained from European Environment Agency (European Environment Agency, 2016).

\section{Results}

\section{Drone video characteristics}

Video category

Table 2 lists the number and percentage of all the categories in the sample used in this research. It is apparent that the distribution is highly skewed: the most popular category is "People \& Blogs", and second and third are "Travel \& Events" and "Film \& Animation". Those three categories of videos constitute more than $2 / 3$ of the entire selection of drone videos in the sample. The fact that the categories "People \& Blogs", "Film \& Animation" and "Science \& Technology" constitute more than half of the drone videos, suggest that drone videos are being categorized from the perspective of their creation, either as a hobby or professional activity. However, the presence of categories, such as "Travel \& Events", 
"Entertainment", "Sports" and others, suggests the understanding of context-specific purpose of the drone videos, on behalf of their creators.

[Insert Table 2 about here]

\section{Video title and description}

Table 3 shows the 50 most frequent nouns found in drone video titles and descriptions. Besides the annotation of geographical features shown, many drone video titles contain the brand of the equipment used for filming. As it can be seen from Table 3 more detailed explanations of drone video creation, procedures and postproduction are shown in video descriptions (aircraft, camera, permission, gimbal, GHz etc.). These findings reconfirm the above-mention suggestion on the importance of drone video creation procedures for uploaders.

[Insert Table 3 about here]

\section{Video length and age}

Figure 1 shows the histogram and normal curve of drone's video length. As can be seen, the drone Histogram exhibits a high positive skewness (1.92) calculated from the sample of drone's video length. The average drone video length is 3.45 minutes $(\sigma 2.41, \mathrm{~N}=614)$. Approximately every fourth drone video (25.73\%) is shorter than 2 minutes, while $69.28 \%$ are up to 4 minutes long.

\section{[Insert Figure 1 about here]}

On average, the drone video age in the sample was about 3 years and 7 months. There were $8.8 \%$ videos older than 5 years. It suggests that, although a relatively new trend for the general market, filming with drones was practiced by early adopters.

\section{Spatial analysis}




\section{Drone video locations and population density}

Figure 2 depicts the spatial distribution of drone videos as point patterns, mapped on the top of the spatial density distribution of UK population as a raster pattern. An overlay of locations and population density showed that $23.38 \%$ of drone videos were shot over areas that did not have registered inhabitants. Still, it does not imply that these areas with no recorded population are in remote areas. The original aim of the study was to use the smallest available spatial resolution size $(1 \times 1 \mathrm{~km})$, which can represent, for example, parks or recreation areas with no registered inhabitants, but within or near densely populated settlements. Figure 2 clearly shows that mostly unpopulated areas far from urbanized centres do not attract many videos.

\section{[Insert Figure 2 about here]}

The overlay of drone video location and land cover/use data showed that about two-thirds of all locations are classified as artificial surfaces (34.2\%) or agricultural areas $(34.0 \%)$ (Figure 3). Discontinuous urban fabric and pastures are the most popular places for drone filming. This is not a surprise, as current regulations in the UK restrict drone flights over densely populated areas or areas used by lots of people. Forested and semi-natural areas are present in the sample with $16.3 \%$. However, mostly open areas are dominant, again because of regulations that require keeping drone in the eyesight of a pilot. Wetlands $(7.0 \%)$ and water bodies $(8.5 \%)$ are present in the list. However, if sub-categories are combined for example, sea and oceans, estuaries, beaches, dunes, sands and bare rocks, sea shores, as distinct geographical areas, are significantly present in the UK drone video sample.

[Insert Figure 3 about here]

Figure 4 shows areas mostly dedicated to recreation with fewer restrictions of drone usage. These were the video locations within nationally designated areas. 
Figure 5 shows that $38.96 \%$ of all drone videos were filmed over protected areas. Areas of outstanding natural beauty (AONB) dominate with $32.9 \%$, followed by national parks $(21.3 \%)$, and sites of specific scientific interest (17.9\%).

[Insert Figure 5 about here]

\section{Discussion}

The results section, above, has presented data gathered to answer the three research questions of this paper, which have implications for both the academic understanding of the role of drone videos in destination marketing, as well as the use of drone videos by practitioners. The following section places these results into the context of the preceding literature review.

Videos filmed by drones, although depicting destinations, are not necessarily intended for purpose of tourism promotion. Indeed, YouTube is not a tourism specific social media site, and videos provided about a destination do not necessarily have a tourism focus (Munar, 2011). Similarly, the results of this analysis show that authors of drone videos, in many cases chose classifications other than "Travel and Events", which implicitly reveals that travelers are not the main expected audience of aerial drone video and that the motivation for video sharing is outside of the scope of tourism. This insight can be relevant for DMOs that could focus on engaging larger, non-tourist, audiences in drone video creation and sharing, although their motivation does not have to be related to destination promotion. Therefore, regardless of the category chosen, which originally helps in video search engine optimization, most aerial drone videos can be considered as partial visual presentations of a destination or a destination activity. The explicit mentioning of place names, landmarks and events at the destination in drone video metadata can be of more relevance. In fact, $80 \%$ of YouTube travel searches focus on destination names and local attractions (Crowel et al., 2014), 
indicating their importance for representing a destination as a form of UGC (Crowel et al., 2014; Mariani et al., 2016; Tussyadiah \& Fesenmaier, 2009).

The research carried out for this study discovered the frequent appearance of technical descriptions and specific drone systems in the video titles. This points towards the fact that there is a growing online community that has formed around drone videos, similar to GoPro videos (Dinhopl and Gretzel, 2016a), made of amateurs, professionals and expert authorities (Coleman, Georgiadou, \& Labonte, 2009). It is not surprising to see greater engagement in this community, as they comment on each other's videos. This is also why it is important to them to provide technical descriptions of the drone videos, as our results suggest. There is often a professional element involved and so these additions are important for establishing expertise or influence in the community (Kozinets, 2002). However, as mentioned earlier, if those videos convey the representation of a destinations (or just a part of it) and if they are attractive to the general public as well, that means that they potentially make a contribution to destination promotion through UGC.

This research revealed the dominance of shorter videos, which was expected, as YouTube is mostly comprised of short video clips. ComScore (2017) reported that in 2014 the duration of the average online content video was 4.4 minutes, but that there is a range in lengths. The presented data shows that the average aerial drone video is one minute shorter if compared to the average online video. By default, users can upload videos to YouTube that are up to 15 minutes long, but with additional requirements, users can upload longer videos. In this sample, only three videos were longer than 15 minutes. The results could be biased by TravelByDrone recommendations to users to upload shorter videos. Looking from the specific point of drone video creation, if drone shooting is restricted to one flight the total video length will be limited by drone flying time, flight condition and regulatory restrictions. 
The results of this analysis suggested that aerial drone videos are not exclusively or dominantly related to certain geographical features. Therefore, the general aerial drone video properties make them suitable for visual presentation of whole destination or its parts. Imposed restrictions on drone usage for certain areas or in certain situations could represent challenge in achieving ubiquitous spatial continuity in Digital Earth presentations. Still, according to geographic concept of destination, the whole country's territory usually cannot be considered as travel destination, as destinations are linked to geographical elements that acts as nucleuses for development (Jovicic, 2016). In that sense, the initiative to set up and expand the use of "geo-fencing" in the UK that acts like an invisible shield around buildings or sensitive areas (e.g., prisons, militarily facilities or airports) and prevents drones from flying in will cover areas that are already away from general interest of tourists. On the other hand, some congested areas that are of tourist interest, as well as areas used for the organized open-air assembly of people at festivals and events, which attract restrictions on drone flights, can be still covered with professional drone filming.

As a form of UGC in tourism, the role of shared aerial drone videos has not previously been examined, despite the growth of drone use (Luppicini \& So, 2016). Aerial drone videos are a kind of UGC that is shared after the tourism experience itself (Munar \& Jacobsen, 2014), and which are not part of the explosion of UGC related to the near ubiquitousness of smart-devices carried by tourists (Urlike Gretzel, 2006; Marchiori \& Cantoni, 2015; Munar, 2011), due to their reliance on specialist equipment that has not yet completely crossed the hobbyist/leisure divide (Bamburry, 2015; Mancosu, 2016). The increasing amount of shared aerial drone videos should be considered part of the new body of information available to researchers to consider their role in destination marketing and to be evaluated along with other kind of online content that has previously been considered (Lim, Chung, \& Weaver, 2012; Munar, 2011). 


\section{Practitioner implications}

Increased consumer access to drones and consequentially, the increased production and sharing of aerial drone videos is not only theoretically interesting, but most importantly it is practically relevant for destination marketing.

Based on the characteristics of drone videos presented above, it is evident that DMOs can benefit from the trend of producing aerial drone videos by drone users. Videos captured from drones could help in differentiating a destination from its competitors (Hay, 2016). As in the case of other UGC, where some DMOs took the role of content curator (Miralbell, AlzuaSorzabal, \& Gerrikagoitia, 2013), shared destination drone videos can be part of a DMO's content management strategies. The procuring, maintaining and using of drones in their own video production, as seen in the New Zealand DMO example, can be supplemented by the leveraging the drone videos filmed by drone users, many of whom are not motivated by factors connected to travel or sharing tourist experiences. These videos are often offered publicly without charge and the "Wow" effect of the new visual perspective can be achieved with various levels of production, outside of the official DMO's content production sources. This research presented a country-level study, but it is assumed that a similar conclusion would be reached in regional or city-level studies, suggesting that these practical implications can be replicated on lower levels of DMO structures.

By providing online platforms and assistance, together with other incentives, DMOs could more engage consumers into creation of this form of UGC, as it was shown earlier that the process of drone video creation is more demanding compared to other forms of video production. DMOs could serve as a "drone ambassadors" and facilitators providing safe flying areas for drone pilots, drone air maps and flight plans to reduce risks and mitigate the 
potential negative effects of drone presence at travel sites, such as privacy violations, noise pollution and other factors that can lead to a perception of drones as a disruptive technology.

\section{Further research and limitations}

This exploratory research attempted to answer the question of what the main characteristics of shared aerial drone videos are, and how they spatially cover a destination, along with their implications for destination marketing practices.

The study of Lim, Chung and Weaver (2012) showed that consumer-generated videos do not carry the same destination brand and have little positive impact compared to destination marketing generated videos. Similar, Google's study revealed that while there is an interest for community-generated travel content on YouTube, most travel-related views (67\%) are branded or professionally related videos. Although the number of views is not always the appropriate metric to measure online video performance, for benchmarking purposes it is reasonable to ascertain how well shared aerial drone videos perform in these terms against others in the same sector. Therefore, for further research it would be interesting to compare viewing metrics of aerial drone videos to other types of YouTube videos, including destination marketing generated videos, to determine whether they perform better or worse, on average (Crane \& Sornette, 2008).

Further studies should be based on larger samples of drone videos from multiple destinations, with multiple methods, to go deeper in answering the question of why this trend is happening and what elements of aerial drone videos cause the biggest impression on viewers. For example, empirical research based on video content analysis is needed to test which element of aerial drone videos appeal the most to viewers. Further qualitative studies could dissect the comments to reveal the motivation for online discussion on drone videos, as it would be interested to find out are they primarily related to production issues, destination 
or both, or the discussion is triggered by other topics. Moreover, in terms of effectiveness, an important additional question would be to ask whether there some other social media variables that influence the viewing of, and response to, aerial drone videos more than the content of the video itself?

The traditional spatial analysis tools used in the paper included spatial distribution maps and descriptive statistics. While these methods can be of use for exploratory analysis, more advanced tools should be used to reveal statistically significant underlying patterns of georeferenced drone videos.

Additional explorations of organizational and human resource capabilities of DMOs to grasp the potential of drone destination videos and to tap in consumers' motivation to use drones are needed, as well as rethinking existing technical and legal issues related to drone usage in the context of destination marketing.

\section{References}

Aaron, T. (2016). Beam me up, Scottie! Drones and the production of a "Third Space" in Tourism. In A. C. C. Lu, Y. Rao, \& D. Gursoy (Eds.), 6th Advances in Hospitality \& Tourism Marketing \& Management Conference (p. 6). Guangzhou: Sun Yat-Sen University; Washington State University. Retrieved from http://www.ahtmm.com/wpcontent/uploads/2016/08/2016.pdf

Almeida, M., Azinheira, J. R., Barata, J., Bousson, K., Ervilha, R., Martins, M., ... Viegas, D. X. (2017). Analysis of Fire Hazard in Campsite Areas. Fire Technology, 53(2), 553575. http://doi.org/10.1007/s10694-016-0591-5

Ayeh, J. K., Au, N., \& Law, R. (2013). “Do We Believe in TripAdvisor?” Examining Credibility Perceptions and Online Travelers' Attitude toward Using User-Generated Content. Journal of Travel Research, 52(4), 437-452.

$\underline{\text { http://doi.org/10.1177/0047287512475217 }}$

Babel, J. (2015). Up in the Air: The Emerging Issue of Drones in the Construction Industry. 
XL Catlin Construction Insider. 5.

Bamburry, D. (2015). Drones: Designed for Product Delivery. Design Management Review, 26(1), 40-48. http://doi.org/10.1111/DREV.10313

Bartha, G., \& Kocsis, S. (2011). Standardization of geographic data: The European INSPIRE Directive. European Journal of Geography, 2(2), 79-89.

Bärtl, M. (2018). YouTube channels, uploads and views. Convergence: The International Journal of Research into New Media Technologies, 24(1), 16-32. http://doi.org/10.1177/1354856517736979

Beadel, S., Shaw, W., Bawden, R., Bycroft, C., Wilcox, F., McQueen, J., \& Lloyd, K. (2018). Sustainable management of geothermal vegetation in the Waikato Region, New Zealand, including application of ecological indicators and new monitoring technology trials. Geothermics, 73, 91-99. http://doi.org/10.1016/J.GEOTHERMICS.2017.11.001

Braitenberg, C., Sampietro, D., Pivetta, T., Zuliani, D., Barbagallo, A., Fabris, P., ... Mansi, A. H. (2016). Gravity for Detecting Caves: Airborne and Terrestrial Simulations Based on a Comprehensive Karstic Cave Benchmark. Pure and Applied Geophysics, 173(4), 1243-1264. http://doi.org/10.1007/s00024-015-1182-y

Bryan, P. (2017). 3D Recording, Documentation and Management of Cultural Heritage. Conservation and Management of Archaeological Sites. 19 (2). 144-146

Canis, B. (2015). Unmanned Aircraft Systems (UAS): Commercial Outlook for a New Industry. Retrieved from http://goodtimesweb.org/industrial-policy/2015/R44192.pdf

Carvão, S. (2010). Embracing user generated content within destination management organizations to gain a competitive insight into visitors' profiles. Worldwide Hospitality and Tourism Themes, 2(4), 376-382. http://doi.org/10.1108/17554211011074038

Chen, C.-H., Nguyen, B., Klaus, P. "Phil,” \& Wu, M.-S. (2015). Exploring Electronic Wordof-Mouth (eWOM) in The Consumer Purchase Decision-Making Process: The Case of Online Holidays - Evidence from United Kingdom (UK) Consumers. Journal of Travel \& Tourism Marketing, 32(8), 953-970. http://doi.org/10.1080/10548408.2014.956165

Cheng, X., Liu, J., \& Dale, C. (2013). Understanding the Characteristics of Internet Short Video Sharing: A YouTube-Based Measurement Study. IEEE Transactions on Multimedia , 15(5), 1184-1194. http://doi.org/10.1109/TMM.2013.2265531 
Chin-Fook, L., \& Simmonds, H. (2011). Redefining Gatekeeping Theory for a Digital Generation. The McMaster Journal of Communication, 8(8), 7-34.

Chung, J. Y., \& Buhalis, D. (2008). Information Needs in Online Social Networks. Information Technology \& Tourism, 10(4), 267-281. http://doi.org/10.3727/109830508788403123

Cole, B., King, S., Ogutu, B., Palmer, D., Smith, G., \& Balzter, H. (2015). Corine land cover 2012 for the UK, Jersey and Guernsey. http://doi.org/10.5285/32533DD6-7C1B-43E1B892-E80D61A5EA1D

Coleman, D. J., Georgiadou, Y., \& Labonte, J. (2009). Volunteered Geographic Information: The Nature and Motivation of Produsers *. International Journal of Spatial Data Infrastructures Research, 4, 332-358. http://doi.org/10.2902/1725-0463.2009.04.art16

ComScore. (2017). comScore Releases January 2014 U.S. Online Video Rankings comScore, Inc. Retrieved August 30, 2017, from http://www.comscore.com/Insights/Press-Releases/2014/2/comScore-Releases-January2014-US-Online-Video-Rankings

Craglia, M., de Bie, K., Jackson, D., Pesaresi, M., Remetey-Fülöpp, G., Wang, C., ... Woodgate, P. (2012). Digital Earth 2020: towards the vision for the next decade. International Journal of Digital Earth, (1), 4-21. http://doi.org/10.1080/17538947.2011.638500

Crane, R., \& Sornette, D. (2008). Viral, Quality, and Junk Videos on YouTube: Separating Content From Noise in an Information-Rich Environment. In AAAI Spring Symposium 2008 - Social Information Processing: Stanford University, CA, USA. Stanford: DBLP. Retrieved from https://vvvvw.aaai.org/Papers/Symposia/Spring/2008/SS-08-06/SS0806-004.pdf

Crowel, H., Gribben, H., \& Loo, J. (2014). Travel Content Takes Off on YouTube. Retrieved August 16, 2017, from https://www.thinkwithgoogle.com/consumer-insights/travelcontent-takes-off-on-youtube/

Cwerner, S. B. (2006). Vertical Flight and Urban Mobilities: the Promise and Reality of Helicopter Travel1. Mobilities, 1(2), 191-215. http://doi.org/10.1080/17450100600726589 
Daugherty, T., Eastin, M. S., \& Bright, L. (2008). Exploring Consumer Motivations for Creating User-Generated Content. Journal of Interactive Advertising, 8(2), 16-25. http://doi.org/10.1080/15252019.2008.10722139

Department for Transport. (2017). Unlocking the UK's High Tech Economy: Consultation on the Safe Use of Drones in the UK Government Response Government Response. Retrieved from https://www.gov.uk/government/uploads/system/uploads/attachment_data/file/631638/u nlocking-the-uks-high-tech-economy-consultation-on-the-safe-use-of-drones-in-the-ukgovernment-response.pdf

Dickey, I. J., \& Lewis, W. F. (2011). An Overview of Digital Media and Advertising. In M. S. Eastin, T. Daugherty, \& N. M. Burns (Eds.), Handbook of Research on Digital Media and Advertising: User Generated Content Consumption. Hershey: IGI Global.

Dinhopl, A., \& Gretzel, U. (2015). Changing Practices/New Technologies: Photos and Videos on Vacation. In Iis Tussyadiah \& Alessandro Inversini (Eds.), Information and Communication Technologies in Tourism 2015 (pp. 777-788). Cham: Springer International Publishing.

Dinhopl, A., \& Gretzel, U. (2016a). Conceptualizing tourist videography. Information Technology \& Tourism, 15(4), 395-410. http://doi.org/10.1007/s40558-015-0039-7

Dinhopl, A., \& Gretzel, U. (2016b). GoPro panopticon: performing in the surveyed leisure experience. In Sandro Carnicelli, David McGillivray, \& Gayle McPherson (Eds.), Digital Leisure Cultures: Critical perspectives (pp. 66-79). New York: Routledge.

DroneDlyers. (2015). The Drone Report 2016 - Droneflyers.com. Retrieved July 28, 2017, from http://www.droneflyers.com/the-drone-report-2016/

EC, E. and I. D.-G. (2008). Study analysing the current activities in the field of UAV. Retrieved from https://ec.europa.eu/home-affairs/sites/homeaffairs/files/elibrary/documents/policies/security/pdf/uav_study_element_2_en.pdf

European Environment Agency. (2016). CDDA v14 Shapefile. Retrieved September 8, 2017 , from https://www.eea.europa.eu/data-and-maps/data/nationally-designated-areasnational-cdda-11/gis-data/cdda-v14-shape-file

Fotis, J., Buhalis, D., \& Rossides, N. (2012). Social Media Use and Impact during the 
Holiday Travel Planning Process. In Matthias Fuchs, Francesco Ricci, \& Lorenzo Cantoni (Eds.), Information and Communication Technologies in Tourism 2012 (pp. 13-24). Vienna: Springer . http://doi.org/10.1007/978-3-7091-1142-0_2

Gao, B., Li, X., Liu, S., \& Fang, D. (2018). How power distance affects online hotel ratings: The positive moderating roles of hotel chain and reviewers' travel experience. Tourism Management, 65, 176-186. http://doi.org/10.1016/J.TOURMAN.2017.10.007

Garrett, J. (2017). Parrot Bebop and Disco Adventurer packs announced • GadgetyNews. Retrieved July 28, 2017, from http://gadgetynews.com/parrot-bebop-disco-adventurerpacks-announced/

Global Market Insights. (2018). Consumer Drone Market worth over \$9bn by 2024. Retrieved August 5, 2018, from https://www.gminsights.com/pressrelease/consumerdrone-market

Goldman Sachs. (2016). Drones: Reporting for Work. Retrieved October 6, 2017, from http://www.goldmansachs.com/our-thinking/technology-driving-innovation/drones/

Gon, M., Pechlaner, H., \& Marangon, F. (2016). Destination management organizations (DMOs) and Digital Natives: the neglected "informal expertise" in web 2.0 implementation and social media presence. Insights from the Italian Friuli Venezia Giulia DMO. Information Technology \& Tourism, 16(4), 435-455. http://doi.org/10.1007/s40558-016-0068-x

Gretzel, U. (2006). Consumer generated content - trends and implications for branding. EReview of Tourism Research, 4(3), 9-11.

Gretzel, U., Fesenmaier, D., Lee, Y. J., \& Tussyadiah, I. (2011). Narrating travel experiences: The role of new media. In S. Richard \& R. S. Philip (Eds.), Tourist Experience: Contemporary Perspectives (pp. 171-182). New York: Routledge.

Gretzel, U., \& Yoo, K. H. (2008). Use and Impact of Online Travel Reviews. In P. O’Connor, W. Höpken, \& U. Gretzel (Eds.), Information and Communication Technologies in Tourism 2008 (pp. 35-46). Vienna: Springer - Verlang. http://doi.org/10.1007/978-3211-77280-5_4

Hay, B. (2016). Drone tourism: A study of the current and potential use of drones in hospitality and tourism. In M. Scerri \& L. K. Hui (Eds.), CAUTHE 2016: The Changing 
Landscape of Tourism and Hospitality: The Impact of Emerging Markets and Emerging Destinations (pp. 49-68). Sydney: Blue Mountains International Hotel Management School.

Hochmair, H. H., \& Zielstra, D. (2015). Analysing user contribution patterns of drone pictures to the dronestagram photo sharing portal. Journal of Spatial Science, 60(1), 7998. http://doi.org/10.1080/14498596.2015.969340

Huertas, A. (2018). How live videos and stories in social media influence tourist opinions and behaviour. Information Technology \& Tourism, 19(1-4), 1-28. http://doi.org/10.1007/s40558-018-0112-0

IMP. (2012). Search Engine Optimization for Youtube Videos. Retrieved August 5, 2018, from https://www.timlorang.com/SEO-for-YouTube-Updated

Ingga, Y. (2016). Drone Videos Lift up the Travel Industry's Charm - AVB Media Asia. Retrieved July 20, 2017, from http://avb.asia/drone-videos-lift-travel-industrys-charm/

Innga, Y. (2016). Drone Videos Lift up the Travel Industry's Charm. Retrieved April 5, 2018, from http://avb.asia/drone-videos-lift-travel-industrys-charm/

Jin, S. V., \& Phua, J. (2016). Making Reservations Online: The Impact of Consumer-Written and System-Aggregated User-Generated Content (UGC) in Travel Booking Websites on Consumers' Behavioral Intentions. Journal of Travel \& Tourism Marketing, 33(1), 101117. http://doi.org/10.1080/10548408.2015.1038419

Johnson, A., \& Arrowsmith, C. (2015). Techniques for Analyzing the Relationship between Population Density and Geographical Features of Interest. Procedia Environmental Sciences, 27, 89-93. http://doi.org/10.1016/j.proenv.2015.07.116

Johnson, J. (2016). How drones are changing the landscape of travel video. Retrieved July 29, 2017, from https://matadoru.com/drones-changing-landscape-travel-video/

Johnson, P. A., Sieber, R. E., Magnien, N., \& Ariwi, J. (2012). Automated web harvesting to collect and analyse user-generated content for tourism. Current Issues in Tourism, (3), 293-299. http://doi.org/10.1080/13683500.2011.555528

Jovicic, D. Z. (2016). Key issues in the conceptualization of tourism destinations. Tourism Geographies, 18(4), 445-457. http://doi.org/10.1080/14616688.2016.1183144 
Kang, M., \& Schuett, M. A. (2013). Determinants of Sharing Travel Experiences in Social Media. Journal of Travel \& Tourism Marketing, (1-2), 93-107. http://doi.org/10.1080/10548408.2013.751237

King, L. M. (2014). Will drones revolutionise ecotourism? Journal of Ecotourism, 13(1), 8592. http://doi.org/10.1080/14724049.2014.948448

Kozinets, R. V. (2002). The Field Behind the Screen: Using Netnography for Marketing Research in Online Communities. Journal of Marketing Research, 39(1), 61-72. http://doi.org/10.1509/jmkr.39.1.61.18935

Kreps, S. E. (2016). Drones: What everyone needs to know. New York, NY: Oxford University Press.

Kwok, L., \& Yu, B. (2013). Spreading Social Media Messages on Facebook: An Analysis of Restaurant Busine.ss-to-Consumer Communications. Cornell Hospitality Quarterly, 54(1), 84-94. http://doi.org/10.1177/1938965512458360

La Bella, L. (2016). Drones and Entertainment. New York, NY. Rosen Publishing Group Lim, Y., Chung, Y., \& Weaver, P. A. (2012). The impact of social media on destination branding: Consumer-generated videos versus destination marketer-generated videos. Journal of Vacation Marketing, 18(3), 197-206. http://doi.org/10.1177/1356766712449366

Litvin, S. W., Goldsmith, R. E., \& Pan, B. (2008). Electronic word-of-mouth in hospitality and tourism management. Tourism Management, 29(3), 458-468. http://doi.org/10.1016/J.TOURMAN.2007.05.011

Lu, Y. (Tracy), Chen, Z. (Wade), \& Law, R. (2018). Mapping the progress of social media research in hospitality and tourism management from 2004 to 2014. Journal of Travel \& Tourism Marketing, 35(2), 102-118. http://doi.org/10.1080/10548408.2017.1350249

Luppicini, R., \& So, A. (2016). A technoethical review of commercial drone use in the context of governance, ethics, and privacy. Technology in Society, 46, 109-119. http://doi.org/10.1016/j.techsoc.2016.03.003

Mancosu, M. (2016). 4 Ways Drones Are Changing The Marketing Industry. Retrieved June 1, 2017, from https://skytango.com/how-drones-are-changing-the-marketing-industry/ 
Månsson, M. (2011). Mediatized tourism. Annals of Tourism Research, 38(4), 1634-1652. http://doi.org/10.1016/j.annals.2011.02.008

Marchiori, E., \& Cantoni, L. (2015). The role of prior experience in the perception of a tourism destination in user-generated content. Journal of Destination Marketing \& Management, 4(3), 194-201. http://doi.org/10.1016/J.JDMM.2015.06.001

Mariani, M. M., Di Felice, M., \& Mura, M. (2016). Facebook as a destination marketing tool: Evidence from Italian regional Destination Management Organizations. Tourism Management, 54, 321-343. http://doi.org/10.1016/j.tourman.2015.12.008

Marine-Roig, E., \& Anton Clavé, S. (2016). A detailed method for destination image analysis using user-generated content. Information Technology \& Tourism, 15(4), 341-364. http://doi.org/10.1007/s40558-015-0040-1

Mendes-Filho, L., Mills, A. M., Tan, F. B., \& Milne, S. (2018). Empowering the traveler: an examination of the impact of user-generated content on travel planning. Journal of Travel \& Tourism Marketing, 35(4), 425-436. http://doi.org/10.1080/10548408.2017.1358237

Miralbell, O., Alzua-Sorzabal, A., \& Gerrikagoitia, J. K. (2013). Content Curation and Narrative Tourism Marketing. In Z. Xiang \& I. Tussyadiah (Eds.), Information and Communication Technologies in Tourism 2014 (pp. 187-199). Cham: Springer International Publishing.

Mirk, D., \& Hlavacs, H. (2014). Using Drones for Virtual Tourism. In D. Reidsma, I. Choi, \& B. Robin (Eds.), Intelligent Technologies for Interactive Entertainment, 6th International Conference, INTETAIN 2014 Chicago, IL, USA, July 9-11, 2014 (pp. 144-147). Cham: Springer.

Mirk, D., \& Hlavacs, H. (2015). Virtual Tourism with Drones: Experiments and Lag Compensation. In Proceedings of the First Workshop on Micro Aerial Vehicle Networks, Systems, and Applications for Civilian Use - DroNet '15 (pp. 45-50). New York, NY.: ACM Press. http://doi.org/10.1145/2750675.2750681

Munar, A. M. (2011). Tourist- created content: rethinking destination branding. International Journal of Culture, Tourism and Hospitality Research, 5(3), 291-305. http://doi.org/10.1108/17506181111156989 
Munar, A. M., \& Jacobsen, J. K. S. (2014). Motivations for sharing tourism experiences through social media. Tourism Management, 43, 46-54.

http://doi.org/10.1016/J.TOURMAN.2014.01.012

Narangajavana, Y., Callarisa Fiol, L. J., Moliner Tena, M. Á., Rodríguez Artola, R. M., \& Sánchez García, J. (2017). The influence of social media in creating expectations. An empirical study for a tourist destination. Annals of Tourism Research, 65, 60-70. http://doi.org/10.1016/J.ANNALS.2017.05.002

PylitZillig, L., Walther, J., Detweiler, C. \& Houston, A. (2016). Public Perceptions of Drones Used for Weather-related Purposes. SciComm 2016 - Lincoln, Nebraska. September 2324, 2016.

Rahman, M. A. (2014). Enabling drone communications with WiMAX Technology. In IISA 2014, The 5th International Conference on Information, Intelligence, Systems and Applications (pp. 323-328). Chania: IEEE. http://doi.org/10.1109/IISA.2014.6878796

Reis, S., Steinle, S., Carnell, E., Leaver, D., Vieno, M., Beck, R., \& Dragosits, U. (2016, January 1). UK gridded population based on Census 2011 and Land Cover Map 2007. NERC Environmental Information Data Centre. http://doi.org/10.5285/61F10C748C2C-4637-A274-5FA9B2E5CE44

Roque, V., \& Raposo, R. (2016). Social media as a communication and marketing tool in tourism: an analysis of online activities from international key player DMO. Anatolia, 27(1), 58-70. http://doi.org/10.1080/13032917.2015.1083209

Rupert Hills, J., \& Cairncross, G. (2011). Small accommodation providers and UGC web sites: perceptions and practices. International Journal of Contemporary Hospitality Management, 23(1), 26-43. http://doi.org/10.1108/09596111111101652

Sakiyama, M., Miethe, T., Leiberman, J., Heen, M. \& Tuttle, O. (2017). Big Hover or Big Brother? Public Attitudes about Drone Usage in Domestic Policing Activities. Security Journal. 30 (4). 1027-1044

Sandvik, K. B., \& Lohne, K. (2014). The Rise of the Humanitarian Drone: Giving Content to an Emerging Concept. Millennium: Journal of International Studies, 43(1), 145-164. http://doi.org/10.1177/0305829814529470

SESAR. (2016). European Drones Outlook Study -Unlocking the value for Europe. 
Retrieved from

http://www.sesarju.eu/sites/default/files/documents/reports/European_Drones_Outlook_ Study_2016.pdf

Shen, H., Liu, X., Yi, S. \& Li, M. (2016). Understanding Tourism Image of Cities through Social Semantic Network Analysis: A Case Study of Shanghai. Chaperon, S. \& MacLeod, N. (eds.). Tourism in Contemporary Cities: Proceedings of the International Tourism Studies Association Conference. University of Greenwich. London. 17-19 August 2016.

Smith, C. (2016). The Photographer's Guide to Drones - O’Reilly Media. San Rafael: Rocky Nook. Retrieved from http://shop.oreilly.com/product/9781681981147.do

Stankov, U., Marković, V., Savić, S., Dolinaj, D., Pašić, M., \& Arsenović, D. (2014). Tourism Resources in Urban Heat Island: A GIS Analysis of Novi Sad, Serbia. In T. Bandrova \& M. Konecny (Eds.), 5th International Conference on Cartography and GIS (pp. 559-567). Sofia: Bulgarian Cartographic Association.

Stark, D. J., Vaughan, I. P., Evans, L. J., Kler, H., \& Goossens, B. (2018). Combining drones and satellite tracking as an effective tool for informing policy change in riparian habitats: a proboscis monkey case study. Remote Sensing in Ecology and Conservation, 4(1), 44-52. http://doi.org/10.1002/rse2.51

Stöcker, C., Bennett, R., Nex, F., Gerke, M., \& Zevenbergen, J. (2017). Review of the Current State of UAV Regulations. Remote Sensing, 9(5), 459. http://doi.org/10.3390/rs9050459

Thelwall, M., Sud, P., \& Vis, F. (2012). Commenting on YouTube videos: From guatemalan rock to El Big Bang. Journal of the American Society for Information Science and Technology, 63(3), 616-629. http://doi.org/10.1002/asi.21679

Tourism New Zealand. (2015). Ultimate 'selfies' reach over 34 million - Tourism New Zealand. Retrieved August 16, 2017, from http://www.tourismnewzealand.com/news/ultimate-selfies-reach-over-34-million/ TravelByDrone. (2017). About. Retrieved May 9, 2017, from http://travelbydrone.com/ Tussyadiah, I. P., \& Fesenmaier, D. R. (2009). Mediating Tourist Experiences: Access to Places via Shared Videos. Annals of Tourism Research, 36(1), 24-40. 
http://doi.org/10.1016/j.annals.2008.10.001

Uşakl1, A., Koç, B., \& Sönmez, S. (2017). How "social” are destinations? Examining European DMO social media usage. Journal of Destination Marketing \& Management, 6(2), 136-149. http://doi.org/10.1016/J.JDMM.2017.02.001

Vannini, P., \& Stewart, L. M. (2017). The GoPro gaze. Cultural Geographies, 24(1), 149155. http://doi.org/10.1177/1474474016647369

Vergouw, B., Nagel, H., Bondt, G., \& Custers, B. (2016). Drone Technology: Types, Payloads, Applications, Frequency Spectrum Issues and Future Developments. In The Future of Drone Use Opportunities and Threats from Ethical and Legal Perspectives (pp. 21-45). The Hague: T.M.C. Asser Press.

Wang, Y., Yu, Q., \& Fesenmaier, D. R. (2002). Defining the virtual tourist community: implications for tourism marketing. Tourism Management, 23(4), 407-417. http://doi.org/10.1016/S0261-5177(01)00093-0

Wozniak, T., Stangl, B., Schegg, R., \& Liebrich, A. (2017). The return on tourism organizations' social media investments: preliminary evidence from Belgium, France, and Switzerland. Information Technology \& Tourism, 17(1), 75-100. http://doi.org/10.1007/s40558-017-0077-4

Ye, Q., Law, R., Gu, B., \& Chen, W. (2011). The influence of user-generated content on traveler behavior: An empirical investigation on the effects of e-word-of-mouth to hotel online bookings. Computers in Human Behavior, 27(2), 634-639. http://doi.org/10.1016/J.CHB.2010.04.014

Yoo, K.-H., Lee, Y., Gretzel, U., \& Fesenmaier, D. R. (2009). Trust in Travel-related Consumer Generated Media. In Wolfram Höpken, Ulrike Gretzel, \& Rob Law (Eds.), Information and Communication Technologies in Tourism 2009 (pp. 49-59). Vienna: Springer. http://doi.org/10.1007/978-3-211-93971-0_5

Zamir, A. R., Hakeem, A., Van Gool, L., Shah, M., \& Szeliski, R. (2016). Introduction to Large-Scale Visual Geo-localization. In A. R. Zamir, A. Hakeem, L. Van Gool, M. Shah, \& R. Szeliski (Eds.), Large-Scale Visual Geo-Localization (pp. 1-18). Cham: Springer. 


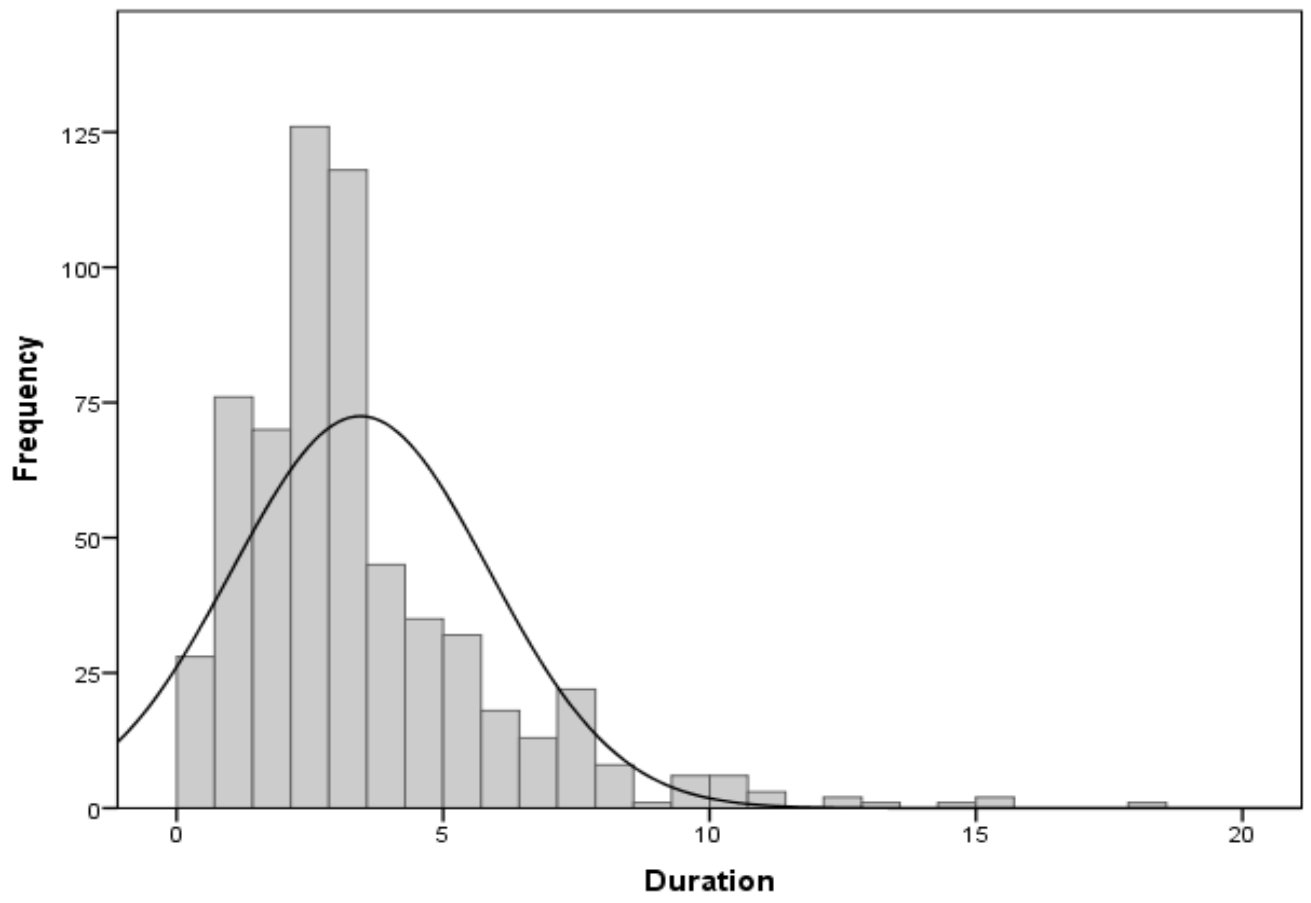

Figure 1. Distribution of aerial drone video length. 


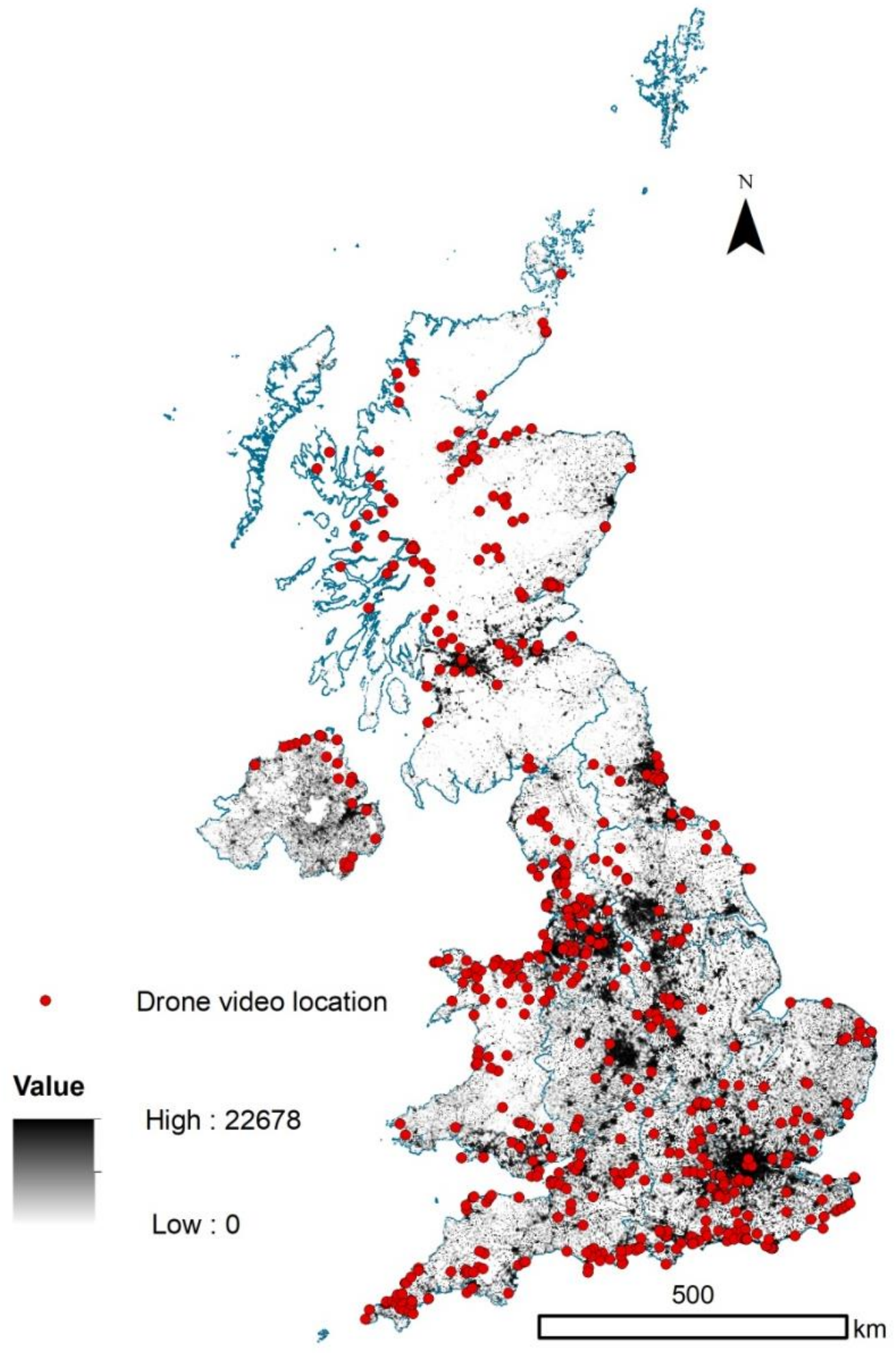

Figure 2. Drone video locations and population density. 


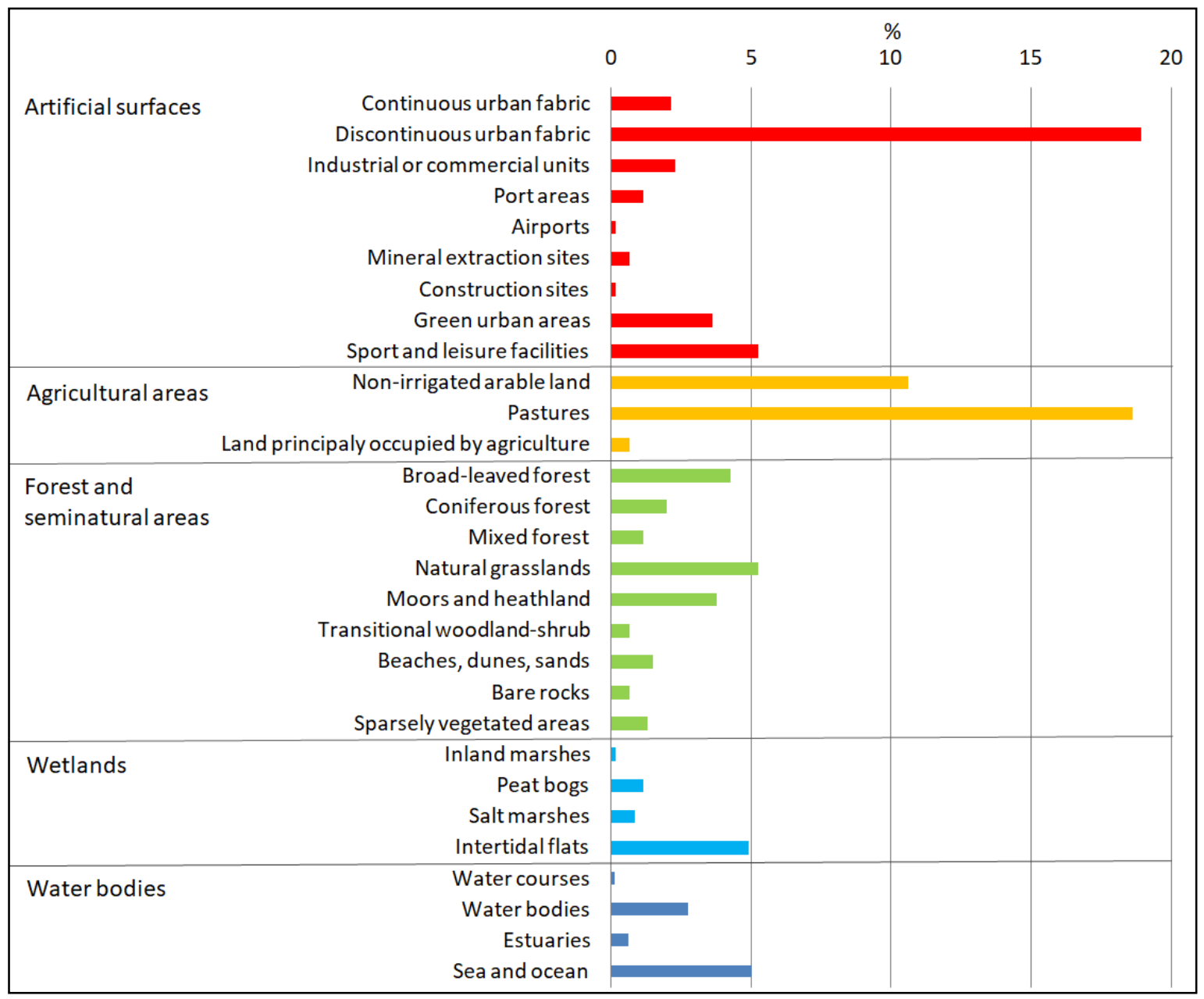

Figure 3. Distribution of drone video locations across CLC categories. 


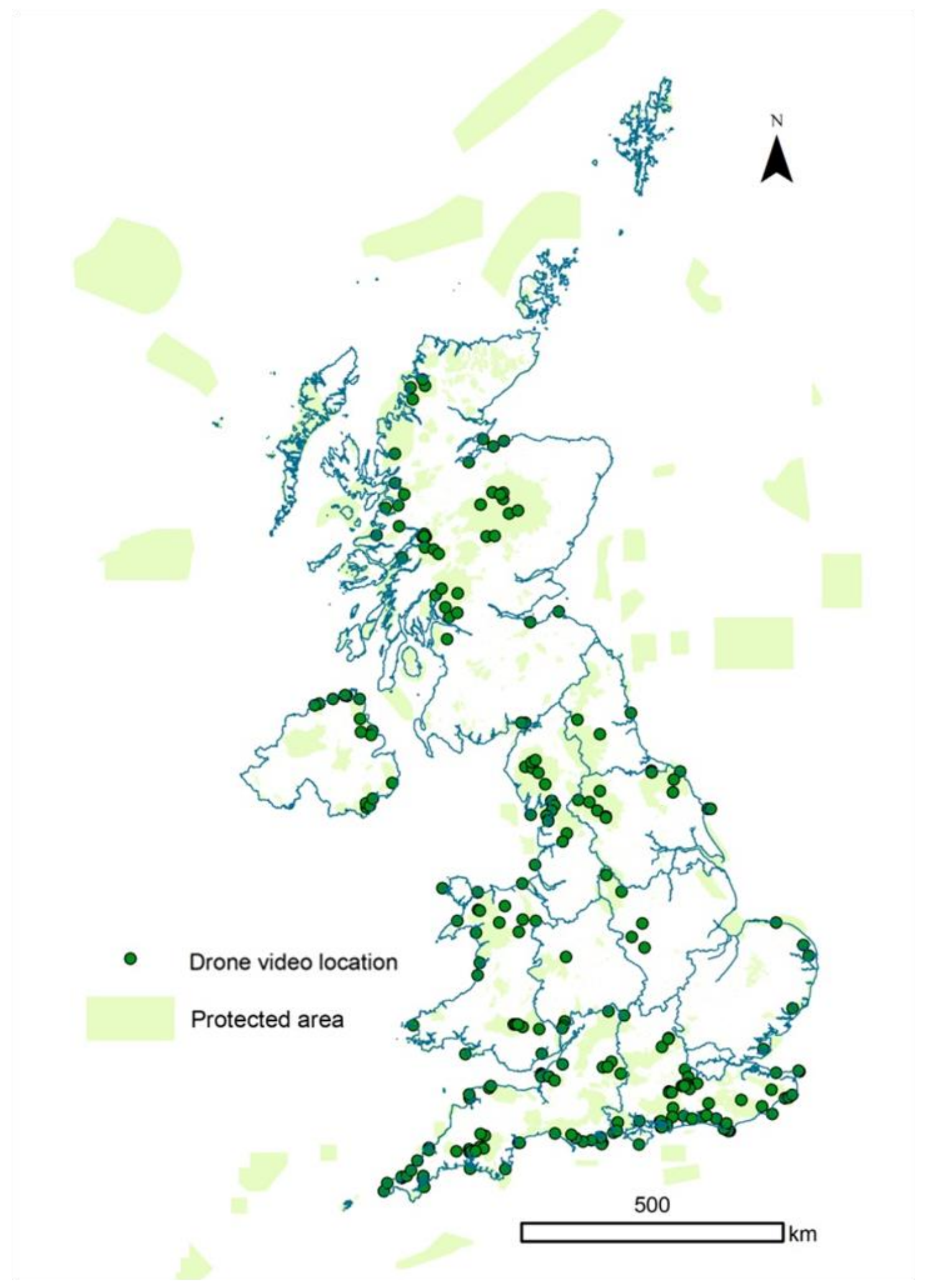

Figure 4. Drone video locations in protected areas (Nationally designated areas) in the UK. 


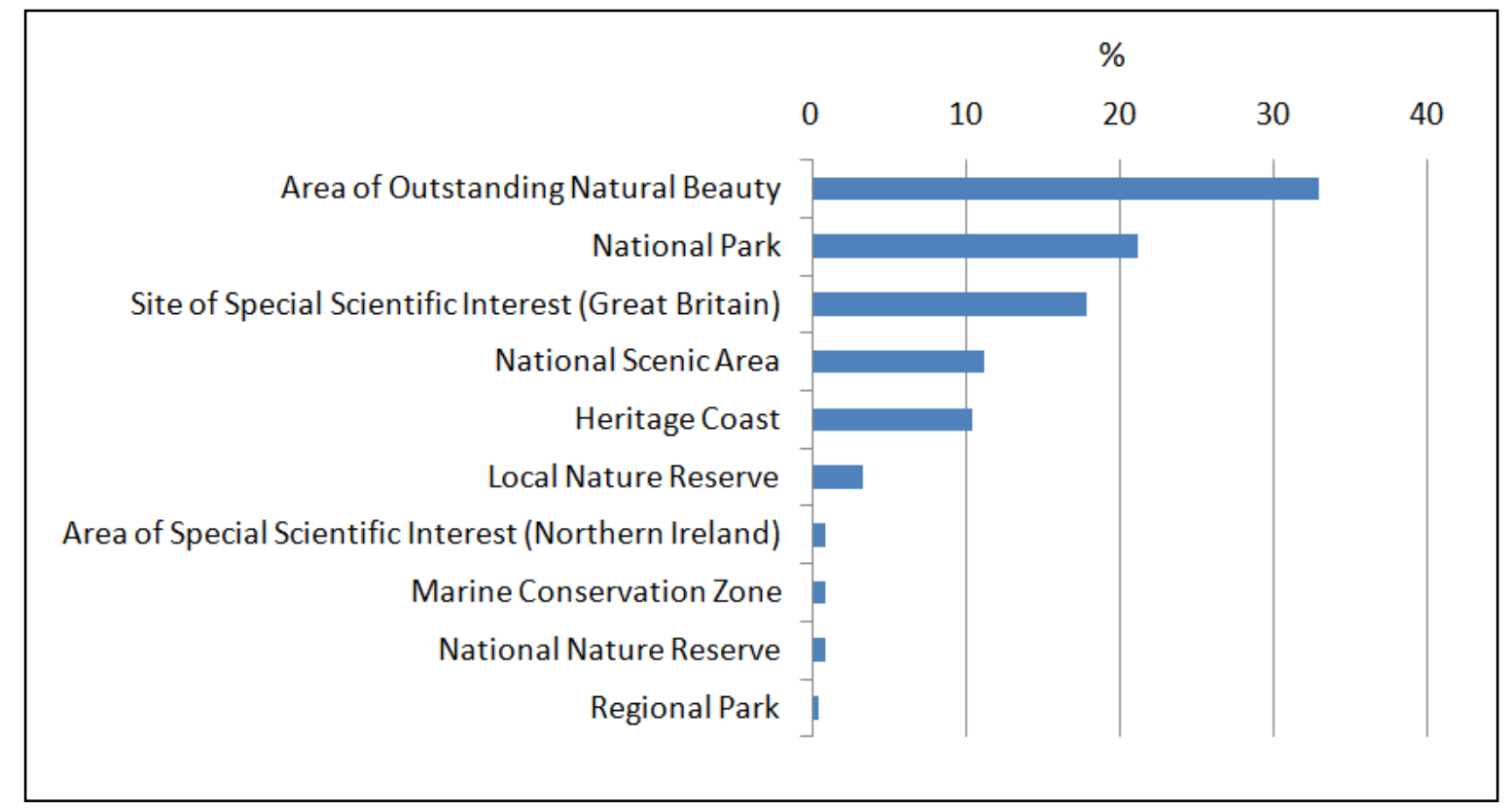

Figure 5. Frequency of aerial drone videos by the different types of protected areas in the UK.

Table 1. Major changes that drones brought to video creation.

\begin{tabular}{|l|l|}
\hline $\begin{array}{l}\text { Aerial filming } \\
\text { perspectives }\end{array}$ & $\begin{array}{l}\text { In drone videos people look at objects and landscapes from a view that they've never } \\
\text { seen before, which is effective in gaining the attention of viewers. For example, rather } \\
\text { than looking down at objects from an angle the "bird's-eye", or "God's eye" view is } \\
\text { created when camera is pointing directly down, creating unique shots that have a lot of } \\
\text { impact on the viewer (Smith, 2016). }\end{array}$ \\
\hline $\begin{array}{l}\text { Access to previously } \\
\text { un-shootable scenarios }\end{array}$ & $\begin{array}{l}\text { Previously, it was difficult or even impossible for amateurs to capture great footage of } \\
\text { locations considered to be off limits, such as volcanoes, cliffs and waterfalls. Now, by } \\
\text { using drones, getting to these difficult and harsh locations is much easier (Innga, 2016). }\end{array}$ \\
\hline $\begin{array}{l}\text { Attractiveness of air } \\
\text { mobility simulations }\end{array}$ & $\begin{array}{l}\text { Flight imagery evokes the age-old dream of human flight (Johnson, 2016). Today the } \\
\text { dream of personal vertical flight lives on in the public imagination of urban mobility. } \\
\text { While this, in reality, is not a viable mobility option, technology allows viewers to } \\
\text { indulge in the dream of flying in a realistic manner (Cwerner, 2006). }\end{array}$ \\
\hline $\begin{array}{l}\text { Democratization of } \\
\text { aerial video production }\end{array}$ & $\begin{array}{l}\text { Prior to the advent of inexpensive consumer drones, aerial video was a costly, heavily } \\
\text { planned and mostly commercial activity that needed the use of helicopters, hot air } \\
\text { balloons, etc. Now, drones with professional video capture devices are available to the } \\
\text { public (Johnson, 2016) }\end{array}$ \\
\hline A new media genre & $\begin{array}{l}\text { The creation of drone videos has led to a new genre in aerial filming, both for } \\
\text { professionals and amateurs (Johnson, 2016). }\end{array}$ \\
\hline Multiple data forms & $\begin{array}{l}\text { Apart from capturing videos, the same drone flight might be used for taking photos or } \\
\text { video can be enchanted by acquiring other data using sensors (for example, 3D, Infra- } \\
\text { Red, georeferencing) (Johnson, 2016; Kreps, 2016). }\end{array}$ \\
\hline
\end{tabular}


Table 2. The frequency of drone videos by YouTube video categories.

\begin{tabular}{|l|c|c|}
\hline Category & Frequency & Percent \\
\hline People and blogs & 197 & $32.08 \%$ \\
\hline Travel and events & 117 & $19.06 \%$ \\
\hline Film and animation & 112 & $18.24 \%$ \\
\hline Entertainment & 67 & $10.91 \%$ \\
\hline Science and technology & 50 & $8.14 \%$ \\
\hline Sports & 31 & $5.05 \%$ \\
\hline Autos and vehicles & 11 & $1.79 \%$ \\
\hline Education & 9 & $1.47 \%$ \\
\hline Comedy & 4 & $0.65 \%$ \\
\hline Gaming & 4 & $0.65 \%$ \\
\hline How to and style & 4 & $0.65 \%$ \\
\hline Music & 4 & $0.65 \%$ \\
\hline Non-profits and activism & 2 & $0.33 \%$ \\
\hline News and politics & 1 & $0.16 \%$ \\
\hline Pets and animals & 1 & $0.16 \%$ \\
\hline Total & 614 & $100.0 \%$ \\
\hline
\end{tabular}


Table 3. Most frequent nouns in drone video titles and descriptions

\begin{tabular}{|c|c|c|c|c|c|c|c|}
\hline \multicolumn{4}{|c|}{ Video titles } & \multicolumn{4}{|c|}{ Video descriptions } \\
\hline Noun & Freq & Noun & Freq & Noun & Freq & Noun & Freq \\
\hline Phantom & 117 & HD & 13 & Phantom & 331 & Scotland & 57 \\
\hline$D J I^{1}$ & 101 & Hill & 13 & $D J I^{1}$ & 257 & film & 54 \\
\hline drone & 56 & Ireland & 12 & UK & 219 & permission & 54 \\
\hline castle & 45 & River & 12 & video & 191 & area & 53 \\
\hline Park & 44 & Bay & 11 & aircraft & 145 & gimbal & 51 \\
\hline flight & 34 & Church & 11 & RPAS $^{2}$ & 120 & Wales & 48 \\
\hline FPV & 33 & Dundee & 11 & GoPro & 110 & $\mathrm{GHz}$ & 46 \\
\hline view & 31 & Lake & 11 & camera & 89 & music & 46 \\
\hline GoPro & 30 & (Phantom Vision) & 11 & metres & 88 & (Phantom & 46 \\
\hline North & 27 & Valley & 11 & $\mathrm{CAA}^{3}$ & 83 & view & 45 \\
\hline video & 27 & Forest & 9 & drone & 80 & location & 44 \\
\hline footage & 22 & Northern (Ireland) & 9 & Facebook & 79 & time & 43 \\
\hline beach & 20 & viaduct & 9 & castle & 78 & river & 42 \\
\hline Wales & 19 & West & 9 & FPV & 75 & $\mathrm{~kg}$ & 41 \\
\hline Birds eye & 18 & Harbour & 8 & (GoPro) & 72 & shot & 41 \\
\hline Air & 17 & Head & 8 & footage & 70 & operator & 40 \\
\hline Cornwall & 17 & South & 8 & park & 69 & RC4 & 40 \\
\hline Dropro & 17 & Country & 7 & quadcopt & 67 & regulations & 40 \\
\hline (Phantom) & 17 & Lancaster & 7 & YouTube & 66 & North & 40 \\
\hline Scotland & 16 & Surrey & 7 & people & 63 & Twitter & 40 \\
\hline UK & 16 & Devon & 6 & Instagra & 62 & channel & 39 \\
\hline bridge & 15 & discovery & 6 & day & 61 & default & 38 \\
\hline (GoPro) Hero & 15 & District & 6 & $\mathrm{HD}$ & 61 & views & 37 \\
\hline coast & 14 & HeliMal & 6 & flight & 58 & bridge & 35 \\
\hline Quadcopter & 14 & House & 6 & person & 57 & feet & 35 \\
\hline
\end{tabular}

1 Dà-Jiāng Innovations Science and Technology Company; ${ }^{2}$ Remotely Piloted Aircraft System;

${ }^{3}$ Civil Aviation Authority, UK; ${ }^{4}$ Radio-controlled) 